\title{
Guilleermo
}

de Colinam

Artículo original ๑ Acceso abierto

\section{Por los senderos de la ficción (o por qué la poesía es más que poesía). Perspectivas para la comprensión de los entes de ficción y su capacidad para resolver problemas \\ On the trails of fiction (or why poetry is more than poetry) \\ Perspectives for understanding fictional entities \\ and their ability to solve problems}

Pierre Guillén Ramírez, OFM ${ }^{\mathrm{i}}$ (1) 우

${ }^{i}$ Vicerrector para la Evangelización de las Culturas; Universidad de San Buenaventura; Cali; Colombia

Correspondencia: Pierre Guillén Ramírez, OFM. Correo electrónico: vicerrector.evangelizacion@usbcali.edu.co

Recibido: $19 / 8 / 2021$

Revisado: 25/8/2021

Aceptado: 26/8/2021

Citar así: Guillén Ramírez, Pierre, OFM (2021). Por los senderos de la ficción (o por qué la poesía es más que poesía). Perspectivas para la comprensión de los entes de ficción y su capacidad para resolver problemas. Revista Guillermo de Ockham 19(2), pp. 355-362.

https://doi.org/10.21500/22563202.5553

Copyright: () 2021. Universidad de San Buenaventura, Cali. La Revista Guillermo de Ockham proporciona acceso abierto a todo su contenido bajo los términos de la licencia Creative Commons AttributionNonCommercial-NoDerivatives 4.0 International (CC BY-NC-ND 4.0).

Conflicto de intereses. Los autores han declarado que no hay conflicto de intereses.

Disponibilidad de datos. Todos los datos relevantes están en el artículo. Para mayor información contactar al autor de correspondencia.

Fondos. Ninguno. Esta investigación no recibió ninguna subvención específica de agencias de financiamiento de los sectores público, comercial o sin fines de lucro.

Descargo de responsabilidad. El contenido de este artículo es responsabilidad exclusiva de los autores y no representa una opinión oficial de su institución ni de la Revista Guillermo de Ockham.
Lo que es dado pensar también se puede enunciar San Buenaventura. I Sent. d. 8.

La filosofía, en verdad, debería escribirse sólo como poesía Wittgenstein, Aforismos. Cultura y valor. (1933-1934)

\section{Resumen}

Este artículo se propone precisar de qué manera es posible hablar de un lenguaje propiamente literario, que contribuye a la resolución de problemas que se plantean en el orden de la acción humana. Para ello, se examina la objeción que Habermas (2017) presenta a la idea de una racionalidad práctica contenida en la literatura y al final se exponen los modos posibles cómo la "ficción" logra configurar de una manera singular lo que solemos llamar "realidad".

Palabras clave: literatura, poesía, filosofía del lenguaje, acción humana, ficción, realidad, ficción literaria.

\section{Abstract}

This article aims to specify how it is possible to speak of a properly literary language that contributes to the resolution of problems that arise in the order of human action. To do this, the objection that Habermas presents to the idea of a practical rationality contained in literature is examined and at the end the possible ways in which "fiction" manages to configure in a singular way what we usually call "reality" are exposed.

Keywords: literature, poetry, philosophy of language, human action, fiction, reality, literary fiction. 


\section{Introducción}

El propósito de este artículo es caracterizar el tipo de discurso contenido en las narraciones literarias, a partir del análisis del estatuto ontológico de los entes de ficción y su capacidad de otorgar sentido a las prácticas humanas. La tesis que vamos a sostener es que, efectivamente, el lenguaje literario induce significados y sentidos de orden extraproposicional y metafórico a los problemas filosóficos, logrando con ello poner en evidencia estratos distintos de la realidad, a los que es imposible acceder con el uso exclusivo de la prosa filosófica convencional, contribuyendo así a la resolución de problemas que se plantean en el orden de la acción humana. Sin embargo, no nos ocuparemos de los puntos de encuentro entre filosofía y literatura, que parecieran hoy indiscutibles, ni de la reducción de una disciplina a la otra, que, dicho sea de paso, no admitimos, sino de la estructura fundamental del lenguaje literario con su configuración ontológica propia y su capacidad de constituir realidades autónomas.

\section{Posibilidad del lenguaje literario}

Deleuze y Guattari (2001), en el séptimo capítulo de ¿Qué es filosofía?, establecen una diferenciación entre el lenguaje filosófico y el literario a partir de su modalidad de creación: "La filosofía es el arte de formar, de inventar, fabricar conceptos" (p. 8), mientras que la literatura, como una forma especial de arte, crea perceptos y afectos, llegando incluso a sostener que "no es que el arte piense menos que la filosofía, sino que piensa por afectos y perceptos" (p. 67). Así, se establece la distinción fundamental y más comúnmente aceptada, entre filosofía y literatura: el concepto y la metáfora.

Ahora bien, en el plano de la filosofía del lenguaje, concretamente a partir de tres perspectivas: 1. la discusión en torno a la significatividad o no de los nombres de ficción (Frege, 1984; Russell, 1919); 2. la vinculación con la teoría de los actos de habla (Austin, 1998; Ohmann y Searle, 1980), y 3. el estatuto ontológico de los mundos posibles (Williamson, 1998), se analiza el problema del lenguaje literario (metafórico o de ficción), tomando en consideración sus particulares estructuras constitutivas respecto de 1. la posibilidad de contar con "sentido" y "referencia" y por ende "significatividad"; 2. su consideración -o no- como "actos ilocucionarios" válidos, y 3 . su existencia como entidades "posibles" pero no "concretas". Expongamos en detalle cada perspectiva.

1. Frege y Russell sentaron las bases de la discusión sobre la pregunta por la significatividad de los nombres de ficción (Santamaría, 2016). Frege, a partir de su estudio sobre los llamados enunciados "no triviales", estableció en su artículo Über Sinn und Bedeutung una suerte de apología de los enunciados literarios al establecer una diferencia entre el sentido (Sinn) y la referencia (Bedeutung) de un nombre de ficción y concluye que "este tipo de nombres no seńalan a ningún individuo, no cuentan con una extensión, pero sí con una intención (descriptores)" (Frege, 1982, como se citó en Santamaría, 2016, p. 229). El "referente" de un nombre es su extensión; es decir, el ejemplar concreto al que el nombre seńala, y el "sentido" son las propiedades, descripciones y relaciones con las que cuenta tal nombre. De modo que, para Frege, los nombres de ficción contenidos en la literatura tienen claramente un sentido en cuanto poseen una intención (comunicativa) dada por el autor de la obra literaria, y ello ya es suficiente para que posean significatividad. Más tarde, Russell refutó la tesis de Frege, en su artículo On denoting (1905), sosteniendo que

(...) todos los enunciados que contienen "nombres" de ficción no son verdaderos nombres propios sino meras descripciones definidas abreviadas, ya que no designan nada en absoluto [...] Los verdaderos nombres propios tienen que poder mostrar (enseñar) el individuo portador del nombre, el ejemplar. Si no hay referente (extensión, ejemplares), como en el caso de los 
aparentes nombres de ficción, tendremos que decir -según Russell-, que no son de ningún modo verdaderos nombres. (Como se citó en Santamaría, 2016, p. 229)

Ambos autores, sin embargo, se inscriben en el problema de la referencialidad de los nombres de ficción. Russell hace depender la significatividad de los enunciados literarios de la existencia física del objeto nombrado y Frege, lo contrario. Esta última consideración recuerda la postura del Wittgenstein de Investigaciones filosóficas, sobre los enunciados de ficción, quien, al refutar las tesis del lenguaje lógicamente perfecto de Russell, sostuvo que la significatividad de los nombres de ficción

(...) no depende de que se pueda dar cuenta o no de ejemplares, sino del uso que de ellos se haga en tal o cual discurso, esto es, en la aceptabilidad o no de tales nombres dentro de un juego de lenguaje, pues todos los términos (palabras o nombres) los usamos de acuerdo al contexto donde son proferidos. (Como se citó en Santamaría, 2016, p. 230)

2. El análisis del lenguaje literario migra después hacia el plano de los llamados actos de habla, es decir, hacia la consideración de su "uso". Desde esta perspectiva, se discute si un enunciado literario puede ser identificado como un acto de habla o, más concretamente, incluso como un "acto ilocucionario"; es decir, aquellos que incluyen "realizar algo" y no solo "decir algo". En esta perspectiva, una novela, por ejemplo, no se comprende simplemente como un acto de "decir algo" con carácter ficcional sino, además, y de manera decisiva, como un acto de carácter social que posibilita la interacción entre los miembros de una comunidad hablante (lenguaje realizativo). Austin, en su obra How to do things with words, escribe poco sobre literatura. Sin embargo, cuando lo hace es para atribuir un estatuto especial a los enunciados literarios al llamarlos "usos no serios" o "usos parásitos" del lenguaje (Austin, 1962, como se citó en Austin, 1998, p. 148). Así, la literatura se constituye en una circunstancia particular (especial) del lenguaje (también la llama "decoloración del lenguaje, no un hablar propio"), pues en una poesía o en un cuento el autor no desea necesariamente que el lector crea que sus afirmaciones son verdaderas, aunque internamente el escrito cuenta con sus propias normas de veracidad y, por ende, que "actúe conforme a lo escrito". En una obra literaria (o también en el libreto de un actor de teatro), se suspenden las condiciones normales de referencia e incluso está ausente todo intento de llevar a cabo un acto ilocucionario típico. Así, dice Austin, "Walt Whitman no incita realmente al águila de la libertad a remontar vuelo" (p. 148).

A partir de estas consideraciones de Austin, Ohmann, en su obra El habla, la literatura y el espacio que media entre ambas, aventura la siguiente hipótesis: "Las obras literarias son discursos en los que están suspendidas las reglas ilocutivas usuales. Si se prefiere, son actos sin las consecuencias normales, formas de decir liberadas del peso usual de los vínculos y responsabilidades sociales" (como se citó en Serna, 2004, p. 85). Así, caracteriza la literatura como un discurso "abstraído" de las circunstancias espacio temporales naturales, en donde el autor "finge" un discurso y el lector acepta ingresar en dicho juego de fingimiento. Por tal motivo, una narración literaria se constituye en un "cuasi acto de habla", en el cual el lector se concentra de forma específica, en los actos locutivos (la trama de ficción, los personajes imaginarios, etc.) y experimenta también sus efectos perlocutivos (la respuesta emocional del lector ante la obra).

Posteriormente, Searle dirá en Speech acts: An essay in the philosophy of language (1969), que "en un discurso de ficción las reglas semánticas son alteradas o en su defecto suspendidas" (citado por Santamaría, 2016, p. 235). De este modo, Searle afirma que un discurso literario en cuanto narración ficcional es un "discurso no serio". Pero con ello no quiere decir que se trata de un discurso engañoso, pues 
(...) cuando un autor de ficción realiza un acto ilocucionario del tipo "en la Plaza Mayor de Salamanca tenemos un sol radiante" no se compromete a que efectivamente esté haciendo buen tiempo en la Plaza Mayor de Salamanca y, de hecho, puede estar cayendo en el momento de la proferencia una tremenda tempestad. El que el discurso sea "no serio" nada tiene que ver con que se quiera mentir al proferir un enunciado de ficción. (Como se citó en Santamaría, 2016, p. 236)

De este modo, para Searle hablar es realizar actos conforme a reglas; en el caso de la literatura, conforme a las mismas reglas dadas por la obra, incluso si se trata de narraciones de ficción.

3. La posibilidad del lenguaje literario también se ubica en el plano de la discusión sobre el llamado "estatuto ontológico de los mundos posibles". Williamson, al estudiar la naturaleza de los mundos posibles; es decir, de los entes de ficción propios del lenguaje literario, se propuso interpretar la llamada fórmula de Barcan (axioma que permite incluir cuantificadores en la lógica modal) como respuesta a la teoría del "actualismo", que sostiene "que el mundo real [actual] contiene todas las entidades que hay. Las presuntas entidades meramente posibles sólo existen si-de una u otra manera- están ya en el mundo real". En este sentido, el actualismo difiere de la tesis que Williamson desarrolló, conocida como los possibilia; es decir, "entidades meramente posibles que no existen en el mundo real, sino solo en otros mundos posibles" (Williamson, 1998, como se citó en Pérez, 2009, p. 73). Los filósofos actualistas rechazan, de plano, la existencia de los entes posibles de las narraciones literarias. Sin embargo, Williamson optó por una postura intermedia entre los possibilia y el actualismo al sostener que en nuestro mundo existen entidades "posiblemente concretas no actualizadas". Esto último se entiende como una tercera alternativa o categoría ontológica, además de la clásica distinción entre entidades concretas y abstractas. Las "entidades posiblemente concretas" de las que habla Williamson, si bien no son concretas, podrían llegar a serlo en un estado especifico de cosas configurado, por ejemplo, por la narración fantástica de una novela.

Entidades "no concretas" significa "no actualizadas"; es decir, que no se cuenta con ejemplares de ellas caminando por el mundo de forma física. Pero las "entidades posiblemente concretas" sí existen en este mundo, pues por el hecho de ser nombradas tienen cierta "subsistencia ontológica". La literatura las crea bajo una singular forma de estar en el mundo (no actualizada) sino posible.

Así, la literatura constituye entes posibles, que no necesariamente son abstractos, sino "no actualizados". Los personajes imaginarios inventados por un autor de literatura nos ponen en contacto con un dominio diferente al plano de lo puramente sensible y aunque adolezcan de falta de "materialidad", no deben ser tenidos sin más como no existentes. En suma, la literatura constituye estados de cosas posibles y las dota de sentido, que tienen lugar en planos diferentes al nuestro y estos tienen plena validez ontológica en cuanto forman parte de un constructo simbólico que posee sus propias reglas de existencia.

\section{Objeción de Habermas}

Ohmann, al referirse a las narraciones literarias, había dicho que se trata de discursos en los que se suspenden las reglas ilocutivas usuales y, por ende, permanecen liberadas del compromiso con las responsabilidades sociales. Habermas (2017) retoma esta idea de Ohmann y sostiene que la literatura no tiene utilidad alguna en la resolución de los problemas que se plantean en el mundo. Por el contrario, le compete la función de "apertura de mundo". En El discurso filosófico de la modernidad de Habermas, se lee: "Los correspondientes sistemas culturales de acción administran las capacidades de solución de problemas de forma similar a como el arte y la literatura las capacidades de 
abrir mundo" (p. 226). Habermas suscribe la idea de que los enunciados literarios solo cuentan con vocación locucionaria en cuanto son autorreferenciales y para que tengan significado deben apelar a sus propias reglas de ficción. Al respecto, sostiene Habermas:

La neutralización de la fuerza ilocucionaria torna virtuales las relaciones [de la literatura] con el mundo, en las que los actos de habla están insertos gracias a su fuerza ilocucionaria, y exime a los participantes en la interacción de entenderse sobre algo en el mundo sobre la base de suposiciones ideales para poder así coordinar sus planes de acción y, con ello, contraer obligaciones ideales relevantes para la interacción. (p. 220)

Ahora bien, según Serna (2004), es preciso advertir que el concepto "apertura de mundo" significa en Habermas algo particular:

El concepto "apertura de mundo" no solo es utilizado por Habermas, sino además por Heidegger y Gadamer. Es menester realizar su deslinde. Mientras que la concepción de "apertura de mundo" de estirpe heideggeriana (previa concepción del mundo como mundo apalabrado) provoca efectos perlocucionarios; la "función de apertura de mundo", atribuida por Habermas a la literatura, limita sus efectos al plano locucionario". (p. 86)

Así las cosas, para Habermas la literatura, ajena a los enunciados ilocucionarios, permanece escindida de los problemas sociales, pues está dominada por la retórica y hace de su función de "apertura de mundo" un fin en sí misma. La narración literaria y la poesía son incapaces de desempeñar una función hermenéutica o transformadora de la realidad. La literatura no logra imprimirle a la ética o a la política rumbo específico alguno. En esta perspectiva, la literatura resulta opuesta a la ciencia, a la técnica, a la moral y al derecho, en cuanto es intuitiva y connotativa y sin pretensiones de universalidad. Esto hace pensar que el lenguaje metafórico es una suerte de discurso "inferior" con relación al lenguaje apodíctico y la literatura queda relegada al rincón de la fantasía. Las narraciones literarias yacen reducidas a una función de ejemplificación; es decir, sirven como ejemplo filosófico de distintas maneras, pero no logran articular una teoría filosófica en cuanto son incapaces de generar conocimiento nuevo. Tal postura habermasiana no solo niega la tesis de que la literatura induce significados y sentidos de orden extraproposicional y contribuye a la resolución de problemas prácticos, sino que pareciera reclamar una reducción de lo racional a lo meramente proposicional y la obligación de trasmutar toda palabra en concepto.

\section{Posibilidad de configurar la realidad y resolver problemas a partir de la ficción literaria}

Queda claro que para Habermas es preciso evitar a toda costa la "contaminación" del discurso filosófico con la retórica literaria. Esta postura es una clara apología al proyecto filosófico de la Ilustración y una abierta oposición al espíritu del Romanticismo, en la que se traslucen pretensiones de verdad, intenciones de rectitud discursiva y autenticidad de los argumentos. El texto literario queda destinado a ser solo una opción técnica del estilo de escribir y una inofensiva teoría de lo bello escindida de la experiencia social humana. Esto, naturalmente, trae consigo serias dificultades. La más evidente de ellas es que se niega el carácter estético de la vida humana en sus complejas relaciones. ¿Nos ha dejado Habermas en un callejón sin salida? Claro que no.

Lo primero es reconocer que nada hay intrínseco al lenguaje metafórico que le impida generar un genuino contacto con lo real, aunque, en general, esto no llegue a suceder. La literatura pone en evidencia la multiplicidad de voces que posee la razón humana y se constituye en clave hermenéutica para entender el carácter estético de la realidad. Incluso, se puede sostener que 
(...) el interés por lo literario y artístico no tendría por qué significar un apresurado abandono del modelo discursivo y analítico -característico de la filosofía-, sino más bien el acceso a un punto de vista más completo, un nuevo método reflexivo, otro límite crítico. (Vásquez, 2006, p. 46)

La literatura posee una particular dimensión ontológica y cognoscitiva, y es, por así decirlo, una "huella antropológica" de síntoma histórico-cultural de determinadas sensibilidades propias de la comunidad de donde emerge como creación artística. Así, una obra literaria permite "leer la sensibilidad de una época o, si se quiere, la condición psicológica de la humanidad en una situación dada” (Vásquez, 2006, p. 48). La razón narrativo-poética es capaz de desempeñar una función hermenéutica e incluso transformadora de la realidad. Los mundos que se crean, por ejemplo, en una novela de ficción (los textos contienen universos semánticos que pueden ser descritos como mundos) poseen una consistencia ontológica propia, constituyen una realidad autónoma, con un telos propio y por ende son capaces de configurar las prácticas humanas, imprimiéndole a la ética o a la política un determinado rumbo.

La obra filosófica de Martha Nussbaum (2005) da cuenta de cómo la literatura puede hacer referencia al mundo real o puede producir mundos posibles, contrafácticos y alternativos. En su obra El conocimiento del amor. Ensayos sobre filosofía y literatura, Nussbaum se pregunta sobre las íntimas conexiones entre las estructuras formales y el contenido que éstas expresan, para una investigación filosófica en el campo de la ética, que vincule la literatura como fuente alternativa pertinente a las concepciones puramente teóricas de corte kantiano o utilitarista, pero sin pervertir su naturaleza simbólica, libre y expresiva. El punto de partida de la investigación ética que se propone Nussbaum es la pregunta: ¿cómo se debería vivir? La literatura, y especialmente la novela, se constituyen en fuente privilegiada de una "racionalidad alternativa" para recorrer el camino de dicha investigación.

Ahora bien, Nussbaum desarrolla la tesis de Henry James y Marcel Proust respecto a la función del estilo literario al abordar los problemas de la vida práctica (si se quiere, ética) de las personas. En este sentido, sostiene que

(...) con respecto a algunas cuestiones interrelacionadas del área de la elección humana, y de la ética entendida en un sentido amplio, existe un conjunto de posturas que constituye un serio candidato a la verdad (y que merece, pues, la atención y el examen de cualquiera que considere seriamente estas cuestiones) cuya encarnación completa, apropiada y (como diría James) "honorable" se encuentra en los términos característicos de las novelas. (2005, p. 34)

Lo anterior, se entiende al considerar la complejidad misma de la vida humana que no puede ser agotada exclusivamente con un análisis teórico abstracto o, si se quiere, filosófico, sino que reclama un tipo diferente de lenguaje, más expresivo, metafórico, colorido y conmovedor, propio de la literatura. Así, el lenguaje literario se constituye -en cuanto producto de la vida práctica y real de los individuos- en la manera más apropiada para lograr una representación precisa y verdadera de la abigarrada existencia humana. Las angustias, las ilusiones, el amor, las pasiones y los sentimientos humanos en general encuentran su expresión más genuina y, por ende, una mejor comprensión ética, en la prosa literaria y no en la fría escritura filosófica convencional.

Nussbaum aboga por un tratamiento de las cuestiones éticas desde el ámbito de la novela literaria, en cuanto las preguntas por el cómo vivir son reales y prácticas y comparten ese talante vital con el trabajo literario. No se trata, sin embargo, de forzar la novela a entrar en una horma filosófica, pues perdería su esencia libre. Incluir la novela en la filosofía moral es poner en relación dinámica la palabra literaria con la indagación sobre la "vida buena", reconociendo, ante todo, que ya las obras literarias están ubicadas, de 
suyo, en esa indagación, pues la labor del escritor expresa una postura valorativa sobre lo humano y sobre el mundo. La literatura pone de manifiesto la relevancia ética de los acontecimientos fortuitos, de lo que se escapa a nuestra voluntad, y pone de manifiesto el valor epistemológico de la emoción. Nussbaum (2005) afirma, incluso, que "la propia estructura de una novela forja una concepción determinada de lo que importa” (p. 65). Las obras literarias no pueden ser concebidas como construcciones recreativas o instrumentos neutrales: ellas configuran el mundo porque permanecen inextricablemente unidas a él.

\section{Conclusiones}

A mi modo de ver, si bien la literatura posee, a diferencia de la prosa filosófica convencional, un potencial imaginativo y emocional muy útil para la reflexión ética y la resolución de problemas, pues nos pone de cara, por ejemplo, a formas alternativas de comprendernos nosotros mismos y nos impulsa a nuevas maneras de relacionarnos intersubjetivamente, por el efecto maravilloso de su esencia libre, tendríamos, pues, que reconocer que ella misma es productora de un tipo de racionalidad diferente que "confecciona mundos" y que expande, por así decirlo, los límites mismos de lo que solemos aceptar como realidad. Ello supone, naturalmente, abandonar la concepción del lenguaje literario como un vehículo de falsedad y de banalidad, y que nada se puede aprender de ella, pues, a diferencia de la perspectiva filosófica tradicional (de cuño moderno ilustrado), no se esfuerza en crear argumentos, análisis y debates en defensa de las presuntas verdades que trabaja.

Claro está que la poesía no se puede limitar a una función instrumental, que la reduce solo a un ejemplo al servicio de teorías filosóficas o de ciertos modelos morales o estéticos. La poesía tampoco es un instrumento de análisis de lo social. Ella no busca de modo alguno, aclarar conceptos y teorías, explicar fenómenos y resolver problemas teóricos argumentando tesis específicas. El poeta, en cambio, usa el lenguaje no para aclarar conceptos, sino para evocar en el lector imágenes, sonidos o ideas de un modo mucho más libre. La literatura tiene la capacidad de poner en evidencia nuevas formas de realidad, que, naturalmente, exigen nuevas formas de pensamiento y de expresión escrita no convencional. Este papel profundo de la literatura, que no lo logra la filosofía, tiene su máxima expresión, sin lugar a dudas, en el establecimiento de un circuito de nuevas relaciones entre pensamiento-mundo y pensamiento-historia.

La literatura, al igual que la filosofía, tiene un compromiso epistemológico y ético con la realidad del mundo que la alberga. Las ideas transforman, direccionan, interpretan y recrean la realidad humana, revelando con ello una fuerte carga social y política. Si bien la literatura posee una clara identidad metafórica y sus personajes son, en su mayoría, producto de la ficción, es capaz de interrogar, polemizar, transgredir y confrontar las dinámicas sociales, económicas y culturales del devenir histórico de un pueblo. Al respecto, sostiene Guadarrama (2017):

El hecho de que en la literatura el escritor en su imaginación construya personajes y situaciones, eso no significa que las haya extraído de ficciones exclusivamente, sino de la realidad socioeconómica, política y cultural en que ha vivido y conoce por lo que se propone de alguna forma concebirla y transmitir algún tipo de verdad sobre ella. (pp. 95-96)

Particularmente en América Latina, la literatura ha desempeñado una importante función social (v. gr. El señor Presidente, de Miguel Ángel Asturias; El otoño del patriarca, de Gabriel García Márquez; Conversación en La Catedral, de Mario Vargas Llosa; etc., tematizan literariamente la figura del dictador). Las novelas, las poesías, el teatro y la música han contribuido a la conformación de nuestras naciones y han acompañado, responsablemente, sus dinámicas políticas y sociales. En concreto, han desempeñado una 
importante labor crítica de la sociedad con el objetivo de contribuir a su mejoramiento social y a su enriquecimiento espiritual. Citando a Jaime Mejía en su obra Rulfo en su lumbre y otros temas latinoamericanos, Guadarrama argumenta que "ni en los momentos más elusivos y estetizantes la literatura aquí dejó de ser polémica, política, testimonial en algún grado y con diverso valor”. (2017, p. 104)

\section{Referencias}

Austin, J. L. (1998). Cómo hacer cosas con palabras. Barcelona: Paidós.

Deleuze, G., y Guattari, F. (2001) ¿Qué es filosofia? Barcelona: Anagrama.

Frege, G. (1984). Ensayos de semántica y filosofía de la lógica. Valdés V. L. (Trad.). España. Tecnos.

Guadarrama, P. (septiembre, 2017). La responsabilidad epistémica y ética en la filosofía y la literatura. En: Hybris, 8, 81-108. doi: 10.5281/zenodo.998072

Habermas, J. (2017). El discurso filosófico de la modernidad. Buenos Aires: Katz

Nussbaum, M. C. (2005). El conocimiento del amor. Ensayos sobre filosofía y literatura (Rocío Orsi Portalo y Juana María Inajeros Ortíz, trads.) Madrid: Mínimo Tránsito

Pérez Otero, M. (2009). El estatus ontológico de los mundos posibles. En: Crítica, 41(122), 69-96. doi: $10.2307 / 3540876$

Russell, B. (1919). Descripciones. En: L. Valdés (Ed.). (1991) La búsqueda del significado. Madrid: Tecnos.

Santamaría Velasco, F. (2016). Hacer mundos: el nombrar y la significatividad. Bogotá: Siglo del Hombre Editores.

Searle, J. (1980). Actos de habla. Ensayo de filosofía del lenguaje. Trad. J. Fillol y E. Ujaldón. En: Valdés Villanueva. L. M. (Ed.) (1991). La búsqueda del significado, pp. 83-93. Madrid: Ed.Tecnos.

Serna Arango, J. (2004). Filosofía y literatura: sendas entrecruzadas. En: Areté, 16(1), 81-99. Recuperado de http://revistas.pucp.edu.pe/index.php/arete/article/view/547/537

Valdés Villanueva, L. M. (Ed.) (1991). La búsqueda del significado. Madrid: Ed. Tecnos.

Vásquez Rocca, A. (2006). El giro estético de la epistemología. La ficción como conocimiento, subjetividad y texto. En: Aisthesis, 40, 45-61. Recuperado de http://www.redalyc.org/articulo. oa?id=163221399003

Williamson, T. (1998). Bare Possibilia. En: Erkenntnis, vol. 48, pp. 257-273. 